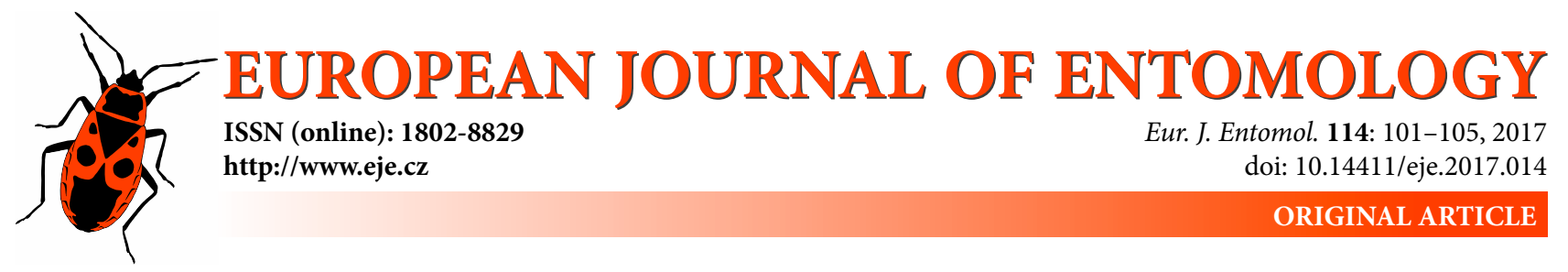

\title{
Electrophysiological and behavioural responses of female Isoceras sibirica (Lepidoptera: Cossidae) to volatiles produced by the plant, Asparagus officinalis
}

\author{
Hongxia LIU, Zhixiong LIU, HaixiA ZHENG, Zerong JIN and Jintong ZHANG* \\ Laboratory of Chemical Ecology, College of Arts and Science, Shanxi Agricultural University, Shanxi, 030801, China; e-mails: \\ sxaulhx@163.com, liuzhixiongnumber1@163.com, zhenghaixia722@163.com, jinzer@126.com, zhangjintong@126.com
}

Key words. Lepidoptera, Cossidae, Isoceras sibirica, Asparagus officinalis, host volatiles, flight tunnel, EAG

Abstract. In herbivorous insects plant volatiles have an important role in locating mates and oviposition sites. The aim of this study was to test the antennal and behavioural responses of females of Isoceras sibirica Alpheraky (Lepidoptera: Cossidae) to the volatiles produced by Asparagus officinalis L. Electroantennographs (EAG) revealed that the antennae of $I$. sibirica respond in a dose dependent way to hexanal, limonene, 2-ethyl-2-hexenal, linalool and a-terpineol. In flight tunnel experiments, 2-ethyl-2-hexenal, a-terpineol, hexanal, $\rho$-cymene and geraniol were significantly more attractive to females of $I$. sibirica than other chemicals. These findings indicate that host volatiles are important for host recognition in I. sibirica.

\section{INTRODUCTION}

Plant volatiles play a significant role in mate and host recognition in phytophagous insects, especially herbivores with narrow host ranges, because they must find a single species of host plant surrounded by a range of non-hosts (Tahvanainen \& Root, 1972; Reed \& Landolt, 2002; Ansebo et al., 2004; Hern \& Dorn, 2004; Natale et al., 2004; Tasin et al., 2005, 2006a, b, 2007). That host volatiles are important in host-plant recognition in polyphagous insects is documented for many species. Eleven chemicals in the shoots of riverbank grape (Vitis riparia Michx.) elicit female grape berry moth (Paralobesia viteana descriptor) to fly upwind flight in flight-tunnel tests (Cha et al., 2008a, b). Volatiles collected from grapevine Vitis vinifera elicit strong antennal responses in females of Lobesia botrana (Denis \& Schiffermüller) and in wind tunnel tests, the main compound (E)- $\beta$-caryophyllene elicit a strong upwind flight (Tasin et al., 2005, 2006a). In addition, synthetic grape volatiles attract mated females of Lobesia Botrana in the field (Anfora et al., 2009). Volatiles from Aquilaria sinensis (Lour.) Gilg (Thymelaeaceae) leaves attract Heortia vitessoides Moore (Lepidoptera: Crambidae), and odour blends of young leaves play an important role in $H$. vitessoides host plant recognition (Qiao et al., 2012). Floral odours elicit significant EAG responses from female Helicoverpa armigera (Hübner) (Lepidoptera: Noctuidae) (Burguiere et al., 2001). Therefore, EAG and behavioural responses to volatiles is an important step towards understanding the role of host-plant volatile chemicals in mediating host recognition by herbivorous insects.

The carpenter worm, Isoceras sibirica Alpheraky (Lepidoptera: Cossidae) is a serious pest of Asparagus officinalis L. This pest can only complete its life cycle on asparagus (Duan et al., 2008). It is likely that females of $I$. sibirica locate oviposition sites using asparagus volatiles. The volatile compounds produced by asparagus have been recorded using solid phase micro extraction in combination with gas chromatography and electroantennograph detection (Sun et al., 2002), but little is known about the role of these volatiles in host plant location by females of I. sibirica.

In this paper, we recorded the antennal and behavioural responses of females of $I$. sibirica to the volatile compounds produced by asparagus, in order to develop a more effective lure based on host-plant volatiles for monitoring and managing this specialist herbivore.

\section{MATERIALS AND METHODS}

\section{Experimental insects}

In late May 2014, I. sibirica pupae were collected from soil $(5-10 \mathrm{~cm}$ in depth) around withered asparagus roots in Jishan County $\left(35^{\circ} 46^{\prime} \mathrm{N}, 111^{\circ} 02^{\prime} \mathrm{E}, 503 \mathrm{~m}\right.$ a.s.1.), Shanxi Province, China. Pupae were segregated by sex, buried at a depth of $10 \mathrm{~cm}$ in sand containing $5-8 \%$ water, and kept at $25 \pm 1^{\circ}, 75 \pm 10 \%$ relative humidity $(\mathrm{RH})$ and a $14 \mathrm{~L}: 10 \mathrm{D}$ photoperiod. After emer-

\footnotetext{
* Corresponding author; e-mail: zhangjintong@126.com.
} 
gence, adult males and females were provided ad lib with a $10 \%$ sucrose solution.

\section{Chemicals}

Chemicals were selected on the basis of the results of GC-MS (Sun et al., 2002) and the bioactive effect the chemicals on moths. The source and level of purity of the chemicals are shown in Table 1.

\section{Electroantennograph detection}

The EAG was recorded using Tang et al.'s (2012) method. Excised antennae, which were prepared by cutting both distal and basic segments, were each suspended between two glass capillary $\mathrm{Ag}-\mathrm{AgCl}$ electrodes filled with a $0.2 \mathrm{M} \mathrm{KCl}$ solution. The antenna was positioned $1 \mathrm{~cm}$ from a glass tube $(0.5 \mathrm{~cm}$ inner diameter, $10 \mathrm{~cm}$ long) that directed test chemicals into a charcoal-filtered humidified air stream $(95 \% \mathrm{RH})$ at $1 \mathrm{~m} \mathrm{~s}^{-1}$ on to each antenna. A CS-05 stimulus controller (Syntech) continuously passed humidified air over the antennae at $11 / \mathrm{min}$. Antennal signals were passed through a high impedance amplifier (CS-05 model, Syntech, the Netherlands) and the EAG responses were initially measured in millivolts (peak height of depolarization) and then converted to normalized responses using the Syntech EAG 2000 program (Syntech, The Netherlands).

The test chemicals were dissolved in paraffin oil at a concentration of $10 \mathrm{mg} \cdot \mathrm{mL}^{-1}$, and concentrations of each of the chemicals of $0.01,0.1,1$ and $10 \mathrm{mg} \cdot \mathrm{mL}^{-1}$ were used in the tests. Ten $\mu \mathrm{L}$ of each chemical solution was placed on a filter paper strip (5 $\times 60 \mathrm{~mm})$ and the solvent allowed to evaporate for $30 \mathrm{~s}$ before the strip was placed inside a glass Pasteur pipette cartridge (14.5 $\mathrm{cm}$ long) used to dispense the test volatiles. Filter papers treated with $5 \mu \mathrm{L}$ of paraffin oil and hexenal was used as the control and standard chemical, respectively. The chemical stimuli were tested randomly, with a stimulus duration time of $0.5 \mathrm{~s}$, followed by a 2 min purge using humidified and purified air to ensure that the antennal receptors recovered. Response to the solvent control was subtracted from all of the normalized responses and the normalized EAG responses were expressed as a percentage of the response to the standard chemical. Each chemical was tested using 15 individual female antennae, and each antenna tested three times. The EAG response data for different chemicals and different concentrations were tested using a one-way ANOVA and compared using Duncan's multiple range test $(\mathrm{P}<0.05)$ in the program SPSS 18.0 (SPSS Inc., Chicago, IL, USA).

\section{Flight-tunnel assay}

The behavioural responses of individual females of I. sibiraca to the eleven chemicals was tested in a poly (methyl methacrylate) flight tunnel $(195 \times 60 \times 60 \mathrm{~cm})$ as described in Cha et al. (2008a). Light was provided by a single red incandescent light

Table 1. Purity and source of the chemicals used.

\begin{tabular}{lrcc}
\hline Standard chemicals & Purity & Company & Country \\
\hline Hexanal & $>95 \%$ & Tokyo Chemical Industry & Japan \\
a-pinene & $95 \%$ & Sigma-Aldrich & USA \\
2-ethyl-2-hexenal & $>94 \%$ & Tokyo Chemical Industry & Japan \\
ß-pinene & $95 \%$ & Sigma-Aldrich & USA \\
P-cymene & $>95 \%$ & Tokyo Chemical Industry & Japan \\
Limonene & $95 \%$ & Sigma-Aldrich & USA \\
Ocimene & $95 \%$ & Sigma-Aldrich & USA \\
Linalool & $95 \%$ & Sigma-Aldrich & USA \\
Nonanal & $97 \%$ & Sigma-Aldrich & USA \\
a-terpineol & $>95 \%$ & Tokyo Chemical Industry & Japan \\
Geraniol & $>96 \%$ & Tokyo Chemical Industry & Japan \\
\hline
\end{tabular}

bulb (light intensity approximately $0.5 \mathrm{lux}$ ). During the experiments, the temperature and relative humidity in the flight tunnel were $25 \pm 1^{\circ}$ and $75 \% \pm 10$, respectively, and the photoperiod $14 \mathrm{~L}$ : 10D. All experiments were done during dusk, as the circadian flight activity of this species peaks in the fourth hour of the scotophase (Liu et al., 2013). Four-day-old females (mating peaks in 3-day-old moths, Liu et al., 2013) from a mating cage were used for flight-tunnel bioassays. We used rubber septa (Baoji Guangren Biotechnology Co., Shanxi, China) loaded with chemicals as stimuli. Ten ng of the stimulus was diluted in $1 \mu \mathrm{l}$ of hexane and placed in the cavity of each septum. Preliminary flight tunnel experiments revealed that the moth responds to this concentration.

At the beginning of the scotophase all female moths were transferred into the climatic chamber housing the wind tunnel. The females were tested for $15 \mathrm{~min}$, using batches of 10-15 females per test stimulus. For each moth, we recorded whether it left the $15 \times 10 \mathrm{~cm}$ cylindrical screen cage and made an upwind flight (more than $50 \mathrm{~cm}$ of tight, zigzag flight to within $10 \mathrm{~cm}$ of the target) as well as whether it landed on or made contact with the target. For data analysis, we categorized each moth based on the most complete behaviour the moth displayed within a period of 8-min. Thus, the behavioural responses of moths were categorized as "no upwind flight" (no directed flight toward the target), "upwind flight" or "landing". Two to four batches of females were tested per day, and each odour source was tested on at least four different days. In total, each chemical was tested using four to six batches of 10-15 females. The responses of female $I$. sibirica to different treatments were compared by fitting a generalised linear model (GENMOD) with upwind flight or landing as dependent variables and different chemicals as fixed independent variables by using binomial distribution with logit link function and maximum likelihood estimation (Proc Glimmix, SAS Institute, 2006). Test effects were compared by using contrast statements and mean \% response, and standard errors were estimated using lsmeans statement with diff option.

\section{RESULTS}

\section{Electroantennogram responses}

Electroantennogram responses of female I. sibirica to different chemicals are shown in Fig. 1. Female moths showed highest EAG responses to 2-ethyl-2-hexenal and the values were higher than the controls to hexanal. Linalool, hexanal and $\alpha$-terpineol were in the second class and there was no difference among them. Limonene, p-cymene, ocimene and nonanal did not differ in their activity, which was greater than $57 \%$ of that of hexanal. The activity recorded for the other chemicals was lower than $30 \%$ of hexanol, except for geraniol ( $43 \%$ of hexanal).

The responses of female I. sibirica to these chemicals were all dose dependent. For every compound, responses to the maximum dose of $10 \mathrm{mg} \cdot \mathrm{mL}^{-1}$ were significantly different from those to other doses (Fig. 2).

\section{Behavioural response of $I$. sibirica females to plant volatiles}

Females responded differently to different single chemicals in terms of upwind flight $(\mathrm{P}<0.001)$ and landing $(\mathrm{P}$ $<0.001$ ) (Fig. 3). Females responded in terms of upwind flight most strongly to 2-ethyl-2-hexenal $(\mathrm{P}=0.99)$ compared to the control, but this was not statistically different from their response to $\alpha$-terpineol $(P=0.85)$ and hexanal $(\mathrm{P}=0.12)$. Attractiveness of $\rho$-cymene to females was 


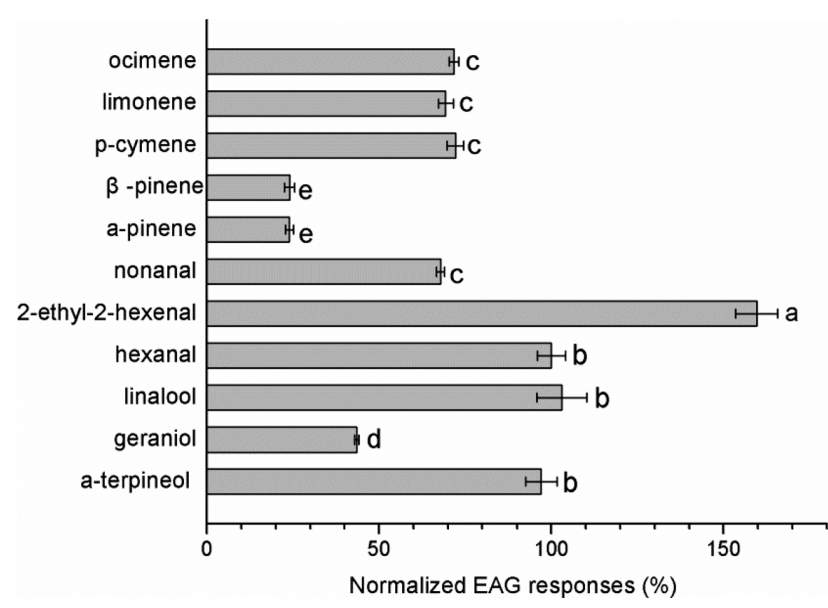

Fig. 1. Mean relative electroantennogram (EAG) response (expressed as a $\%$ of that recorded in the control plus standard deviations, see text) of females of $I$. sibiraca to 11 chemicals. The test of each chemical was done using the antennae of 15 females and the response of each antenna was recorded three times. Bars followed by different letters differ significantly based on an ANOVA followed by Duncan's new multiple range test $(P<0.05)$.

significantly lower than to hexanal ( $\mathrm{P}<0.001)$, but not statistically different from the response to geraniol $(\mathrm{P}=$ $0.71)$, which was significantly greater than to nonanal ( $P$ $<0.001)$. Limonene was significantly less attractive to females than nonanal $(\mathrm{P}=0.05)$, but not statistically different from the response to ocimene $(\mathrm{P}=0.15)$ and linalool $(\mathrm{P}=$ $0.11)$. Attractiveness of $\alpha$-pinene and $\beta$-pinene to females was not statistically significant. The percentage of females that landed on the geraniol target was significantly higher than on the 2-ethyl-2-hexenal target $(\mathrm{P}<0.001)$, but there were no statistical differences between the landings recorded on 2-ethyl-2-hexenal and hexanal $(P=0.12)$, hexanal and $\alpha$-terpineol $(\mathrm{P}=0.08)$ and $\alpha$-terpineol and $\rho$-cymene targets $(P=0.05)$, and no landings were recorded on the targets with other chemicals.

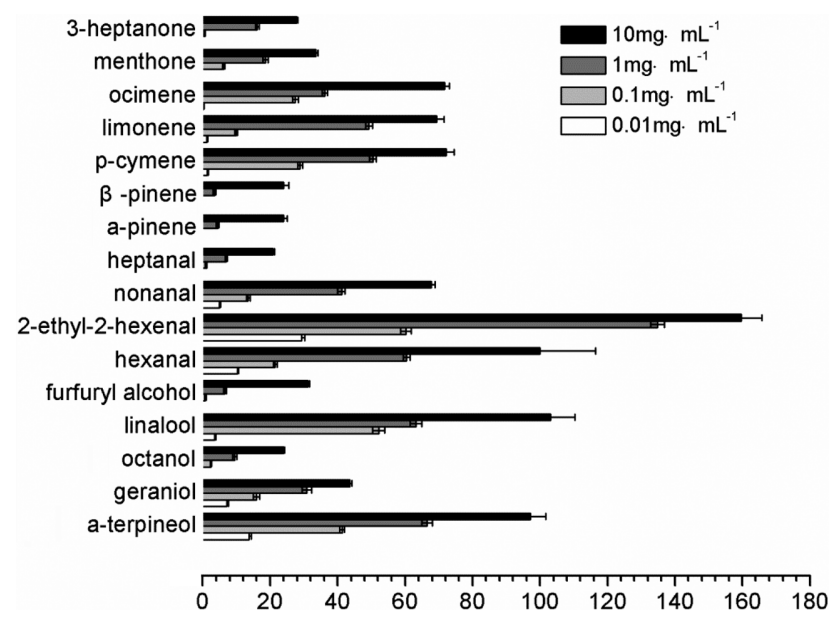

Fig. 2. Mean relative electroantennogram response (expressed as a $\%$ of that recorded in the control plus standard deviations, see text) of females of $I$. sibiraca to 11 chemicals at four different doses $\left(0.01,0.1,1\right.$ and $\left.10 \mathrm{mg} \cdot \mathrm{mL}^{-1}\right)$. The test of each chemical was done using the antennae of 15 females and the response of each antenna was recorded three times.

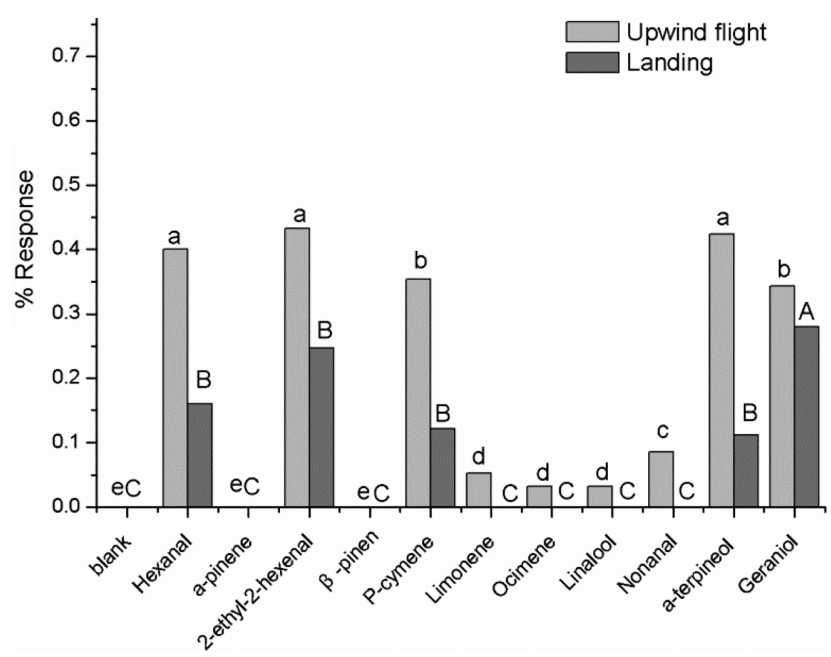

Fig. 3. Flight tunnel response (\%) of females $I$. sibiraca to the different chemicals listed below the $X$ axis $(N=636)$. Different letters (capital letters for upwind flight and small letters for landing) on bars indicate significant differences in the responses $(P<0.05)$.

\section{DISCUSSION}

The aim of this research was to understand the role of host-plant volatiles in selection of a host by females of $I$. sibirica and develop a synthetic lure based on host volatiles for monitoring female flight activity in the field. Females of I. sibirica were strongly attracted to the chemicals 2-ethyl-2-hexenal, linalool, hexanal, $\alpha$-terpineol, limonene, p-cymene, ocimene, nonanal and geraniol at a dose of $10 \mathrm{mg} \cdot \mathrm{mL}^{-1}$. In behavioural tests, five of these chemicals, namely 2-ethyl-2-hexenal, $\alpha$-terpineol, hexanal, $\rho$-cymene and geraniol, were behaviourally active in the wind tunnel. Many of these chemicals are known to attract other Lepidoptera (Gabel et al., 1992; Rojas, 1999; Bruce \& Cork, 2001; Fraser et al., 2003; Olsson et al., 2005; Tasin et al., 2007). The monoterpenes $\rho$-cymene and terpineol elicit responses in $70 \%$ of the females of the European grapevine moth (Gabel et al., 1992). Rojas (1999) reports that $\alpha$-terpinene elicits upwind flight and that the aliphatic compound (E)-2-hexenal elicits upwind flight and landing in mated females of Mamestra brassicae (L.).

Among the chemicals tested, although 2-ethyl-2-hexenal, hexanal and $\alpha$-terpineol attracted more females than other chemicals, the upwind flight responses were only $43.2 \%$ and $42.4 \%$ respectively. The low responses recorded indicate that in addition to specific plant odours a particular ratio of different chemicals might be more attractive. Visser (1986) and Bruce et al. (2005) argue that the ratio of the chemicals in plant volatiles provide the specific recognition cues. This has been shown for females of L. botrana, where the ratio of 3 synthetic grapevine volatiles is important for host recognition in this species (Tasin et al., 2006b). Furthermore, in the behaviour test, only a few females arrived at the source of the stimulus. A possible explanation is that, in nature, background odour from plants surrounding the host will interfere with the recognition process, in addition flight tunnel and biological factors, such as wind speed, diel periodicity and mating status need to be considered. 
Cha et al. (2008a) report that the behaviour of females depended on wind speed and mated females were more likely to land on the source than unmated females.

Our finding that females of I. sibirica respond to host plant volatiles, indicate it is possible to develop synthetic host plant lures and these volatiles will be useful in future studies on the processing of olfactory information.

ACKNOWLEDGEMENTS. This research was supported by a Science and Technology Research Project (No. 2015021148) in Shanxi Province (China) and the Research Foundation for the Introduction of Talent of Shanxi Agricultural University (Grant no. 2014ZZ09).

\section{REFERENCES}

Anfora G., Tasin M., De Cristofaro A., Ioriatti C. \& Lucchi A. 2009: Synthetic grape volatiles attract mated Lobesia botrana females in laboratory and field bioassays. - J. Chem. Ecol. 35: 1054-1062.

Ansebo L., Coracini M.D.A., Bengtsson M., Liblikas I., Ramirez M., Borg-Karlson A.K., Tasin M. \& Witzgall P. 2004: Antennal and behavioural response of codling moth Cydia pomonella to plant volatiles. - J. Appl. Entomol. 128: 488-493.

Anton S., Dufour M.C. \& Gadenne C. 2007: Plasticity of olfactory guided behaviour and its neurobiological basis: lessons from moths and locusts. - Entomol. Exp. Appl. 123: 1-11.

Baur R., FeEny P. \& Stadler E. 1993: Oviposition stimulants for the black swallowtail butterfly: Identification of electrophysiologically active compounds in carrot volatiles. - J. Chem. Ecol. 19: 919-937.

Berlocher S.H. \& Feder J.L. 2002: Sympatric speciation in phytophagous insects: moving beyond controversy? - Annu. Rev. Entomol. 47: 773-815.

BRUCE T.J. \& CoRK A. 2001: Electrophysiological and behavioral responses of female Helicoverpa armigera to compounds identified in flowers of African marigold, Tagetes erecta. - J. Chem. Ecol. 27: 1119-1131.

Burguiere L., Marionpoll F. \& Cork A. 2001: Electrophysiological responses of female Helicoverpa armigera (Hubner) (Lepidoptera: Noctuidae) to synthetic host odours. - J. Insect Physiol. 47: 509-514.

CARDÉ R. \& Willis M. 2008: Navigational strategies used by insects to find distant, wind-borne sources of odor. $-J$. Chem. Ecol. 34: 854-866.

Casadoa D., Gemenob C., Avillab J. \& Ribab M. 2006: Daynight and phenological variation of apple tree volatiles and electroantennogram responses in Cydia pomonella (Lepidoptera: Tortricidae). - Environ. Entomol. 35: 258-267.

Cha D.H., Hesler S.P., Moser C.L., Nojima S., Linn C.E., RoeLOFS W.L. \& Loeb G.M. 2008a: Flight tunnel responses of female grape berry moth (Paralobesia viteana) to host plants. - J. Chem. Ecol. 34: 622-627.

Cha D.H., Nojima S., Hesler S.P., Zhang A., Linn C.E., Roelofs W.L. \& Loeb G.M. 2008b: Identification and field evaluation of grape shoot volatiles attractive to female grape berry moth (Paralobesia viteana). - J. Chem. Ecol. 34: 1180-1189.

Duan G.Q., Zhang Z.B., Zhang H.J., Du Y.Q., Hua B.Z. \& Ma L.P. 2008: The bionomics of Isoceras sibirica. - Chin. Bull. Entomol. 45: 397-400.

Fraser A.M., Mechaber W.L. \& Hildebrand J.G. 2003: Electroantennographic and behavioral responses of the sphinx moth Manduca sexta to host plant volatiles. - J. Chem. Ecol. 29: $1813-1833$
Gabel B., Thiery D., Suchy V., Marion-Poll F., Hradsky P. \& FARKAS P. 1992: Floral volatiles of Tanacetum vulgare L. attractive to Lobesia botrana Den. et Schiff. females. - $J$. Chem. Ecol. 18: 693-701.

Hansson B.S., Van Der Pers J.N.C. \& Lofqvist J. 1989: Comparison of male and female olfactory cell response to pheromone compounds and plant volatiles in the turnip moth, Agrotis segetum. - Physiol. Entomol. 14: 147-155.

Hern A. \& Dorn S. 2004: A female-specific attractant for the codling moth, Cydia pomonella, from apple fruit volatiles. Naturwissenschaften 91: 77-80.

Linn C.E., Feder J.L., Nojima S., Dambroski H.R., Berlocher S.H. \& Roelofs W.L. 2003: Fruit odor discrimination and sympatric host race formation in Rhagoletis. - Proc. Natn. Acad. Sci. U.S.A. 100: 11490-11493.

Liu H.X., Liu Z.X., Jing X.Y., Yan M.H., Liu J.L. \& Zhang J.T. 2014: Scanning electron microscopy studies of antennal sensilla of Isoceras sibirica Alpheraky (Lepidoptera, Cossidae). - Ann. Soc. Entomol. Fr. 50: 350-357.

Natale D., Mattiacci L., Pasqualini E. \& Dorn S. 2004: Apple and peach fruit volatiles and the apple constituent butyl hexanoate attract female oriental fruit moth, Cydia molesta, in the laboratory. - J. Appl. Entomol. 128: 22-27.

Olsson C., Anderbrant O. \& Lofstedt C. 2005: Electrophysiological and behavioral responses to chocolate volatiles in both sexes of the pyralid moths Ephestia cautella and Plodia interpunctella. - J. Chem. Ecol. 31: 2947-2961.

Piñero J.C. \& Dorn S. 2009: Response of female oriental fruit moth to volatiles from apple and peach trees at three phenological stages. - Entomol. Exp. Appl. 131: 67-74.

Qiao H., Lu P., Chen J., Ma W., Qin R. \& Li X. 2012: Antennal and behavioural responses of Heortia vitessoides females to host plant volatiles of Aquilaria sinensis. - Entomol. Exp. Appl. 143: 269-279.

Raguso R.A., Light D.M. \& Picherskyi E. 1996: Electroantennogram responses of Hyles lineata (Sphingidae: Lepidoptera) to volatile compounds from Clarkia breweri (Onagraceae) and other moth-pollinated flowers. - J. Chem. Ecol. 22: 17351766.

ReEd H.C. \& Landolt PJ. 2002: Attraction of mated female codling moths (Lepidoptera: Tortricidae) to apples and apple odor in a flight tunnel. — Fla Entomol. 85: 324-329.

RoJAS J.C. 1999: Electrophysiological and behavioral responses of the cabbage moth to plant volatiles. - J. Chem. Ecol. 25: $1867-1883$.

Rosillo L., Salinas M., Garijo J. \& Alonso G. 1999: Study of volatiles in grapes by dynamic headspace analysis: Application to the differentiation of some Vitis vinifera varieties. $-J$. Chromatogr. (A) 847: 155-159.

Sun R., Wang Y., Chin C.K. \& Garrison S.A. 2002: Volatile compounds in Asparagus officinalis L. - Acta Horticult. 589: 257-266.

Schmidtbusser D., Von Arx M. \& Connetable S. 2011: Identification of host-plant chemical stimuli for the European grape berry moth Eupoecilia ambiguella. - Physiol. Entomol. 36: 101-110.

TAhVAnainen J.O. \& Root R.B. 1972: The influence of vegetational diversity on the population ecology of a specialized herbivore, Phyllotreta cruciferae (Coleoptera: Crysomelidae). Oecologia 10: 321-346.

TANG R., Su M. \& Zhang Z. 2012: Electroantennogram responses of an invasive species fall webworm (Hyphantria cunea) to host volatile compounds. - Chin. Sci. Bull. 57: 4560-4568. 
Tasin M., Anfora G., Loriatti C., Carlin S., De Cristofaro A., Schmidt S., Bengtsson M., Versini G. \& Witzgall P. 2005: Antennal and behavioral responses of grapevine moth Lobesia botrana females to volatiles from grapevine. - J. Chem. Ecol. 31: 77-87.

Tasin M., Backman A. \& Coracini M. 2007: Synergism and redundancy in a plant volatile blend attracting grapevine moth females. - Phytochemistry 68: 203-209.

Tasin M., Backman A. \& Bengtsson M. 2006a: Essential host plant cues in the grapevine moth. - Naturwissenschaften $\mathbf{9 3}$ 141-144.

Tasin M., Bäckman A.C., Bengtsson M., Varela N., Ioriatt C. \& Witzgall P. 2006b: Wind tunnel attraction of grapevine moth females, Lobesia botrana, to natural and artificial grape odour. - Chemoecology 16: 87-92.

Tichenor L.H. \& Seigler D.S. 1980: Electroantennogram and oviposition responses of Manduca sexta to volatile components of tobacco and tomato. - J. Insect Physiol. 26: 309-314.
Topazzini A., Mazza M. \& Pelos P. 1990: Electroantennogram responses of five Lepidoptera species to 26 general odourants. - J. Insect Physiol. 36: 619-624.

VAN Der Pers J.N.C. 1981: Comparison of electroantennogram response spectra to plant volatiles in seven species of Yponomeuta and in the tortricid Adoxophyes orana. - Entomol. Exp. Appl. 30: 181-192.

Van Loon J.A., Frentz W.H. \& Van EeuwiJK F.A. 1992: Electroantennogram responses to plant volatiles in two species of Pieris butterflies. - Entomol. Exp. Appl. 62: 253-260.

VISSER J.H. 1986: Host odor perception in phytophagous insects. - Annu. Rev. Entomol. 31: 121-144.

Zhang Z., Bian L., Sun X., Luo Z., Xin Z., Luo F. \& Chen Z. 2015: Electrophysiological and behavioural responses of the tea geometrid Ectropis obliqua (Lepidoptera: Geometridae) to volatiles from a non-host plant, rosemary, Rosmarinus officinalis (Lamiaceae). - Pest Manag. Sci. 71: 96-104.

Received August 25, 2016; revised and accepted January 25, 2017 Published online February 7, 2017 